\title{
USE OF CLOZAPINE IN BRAZILIAN PATIENTS WITH PARKINSON'S DISEASE
}

\author{
Laura Gomide', Arthur Kummer ${ }^{2}$, Francisco Cardoso ${ }^{3}$, Antonio Lucio Teixeira ${ }^{4}$
}

\begin{abstract}
Clozapine has been used as an attempt to manage levodopa complications in advanced Parkinson's disease (PD). To investigate the use of clozapine in this context in a Brazilian sample, a retrospective chart review was carried out at the Movement Disorders Clinic from the Federal University of Minas Gerais. This study enrolled 43 PD patients who used or were in use of clozapine. Patients had a mean age of 64 years and a mean UPDRS score of 55. Clozapine was indicated for dyskinesias in 17 patients, for psychosis in 15 and for both reasons in 11. The average maximum dose was $70 \mathrm{mg} /$ day. Twenty six patients used it for a mean of 3.5 years. Twenty nine presented an improvement of their condition, 9 remained clinically stable. Twenty subjects interrupted the use of clozapine, being 9 due to adverse effects. Clozapine may play a role in the management of motor and psychiatric complications in PD, but it is associated with low tolerability.
\end{abstract}

KEY WORDS: Parkinson's disease, clozapine, dyskinesia, psychosis.

\section{Uso da clozapina em pacientes brasileiros com doença de Parkinson}

Resumo - A clozapina vem sendo utilizada na doença de Parkinson (DP) avançada para controle das complicações causadas pela levodopa. Com o objetivo de investigar o emprego da clozapina nesse contexto em amostra de pacientes brasileiros, um estudo retrospectivo foi realizado no Ambulatório de Distúrbios do Movimento da Universidade Federal de Minas Gerais. Este estudo incluiu 43 pacientes que usaram clozapina, apresentando idade média de 64 anos e uma média de 55 pontos no UPDRS. A clozapina foi indicada para discinesias em 17 pacientes, para psicose em 15 e para ambos os motivos em 11. A média da dose máxima empregada foi de cerca de $70 \mathrm{mg} /$ dia. Vinte e seis pacientes usaram a medicação por uma média de 3,5 anos. Houve melhora do quadro clínico em 29 pacientes, 9 permaneceram com quadro clínico estático. 0 tratamento foi interrompido em 20 pessoas, sendo 9 por efeitos adversos. Apesar de a clozapina ser eficaz no controle das complicações motoras e psiquiátricas na DP, seu uso está associado com baixa tolerabilidade.

PALAVRAS-CHAVE: doença de Parkinson, clozapina, discinesia, psicose.

The use of levodopa is of paramount importance in moderate to advanced Parkinson's disease (PD) in order to control the motor symptoms. However, its chronic use can lead to complications such as dyskinesias, clinical fluctuation and psychiatric symptoms'. One attempt to manage these complications, especially regarding drug-induced psychosis, includes the use of atypical neuroleptics. However, until now, only clozapine has showed efficacy in these situations without worsening motor impairment ${ }^{2-4}$.

Clozapine has proved its benefits in small retrospective studies and in some double-blind placebo-controlled trials ${ }^{2}$. Nevertheless, clozapine can cause a series of side effects that limit its use ${ }^{5}$.
There are no Brazilian studies which analyzed clozapine use in PD. The objective of this study was to examine the characteristics of patients in use of clozapine as well as its efficacy and tolerability in PD patients followed at the Movement Disorders Clinic from the University Hospital at Federal University of Minas Gerais (UFMG).

\section{METHOD}

A retrospective analysis of patients with clinically defined PD who used or were in use of clozapine was performed through systematic chart review. A predetermined protocol was fulfilled for each patient. Clinical and demographic data were carefully collected. The scores of Unified Parkinson's Disease Rating Scale

Movement Disorders Clinic, Service of Neurology, University Hospital and Group of Neurology, Department of Internal Medicine, School of Medicine, Federal University of Minas Gerais (UFMG), Belo Horizonte, Brazil: 'Physician; ${ }^{2}$ Psychiatrist; ${ }^{3}$ Neurologist, Professor of the Department of Internal Medicine; ${ }^{4}$ Neurologist and Psychiatrist, Professor of the Department of Internal Medicine.

Received 16 May 2008, received in final form 16 July 2008. Accepted 26 July 2008.

Dr. Antonio Lúcio Teixeira - Departamento de Clínica Médica / Faculdade de Medicina / UFMG - Avenida Alfredo Balena 190 - 30130 -100 Belo Horizonte MG - Brasil.E-mail: altexr@gmail.com 
(UPDRS), Hoehn \& Yahr staging (H\&Y) and Schwab \& England Activities of Daily Living Scale (ADL) were also collected. The comorbidities, medications in use, indications to initiate clozapine, doses, period of use, adverse effects and results observed by patients, caregivers or neurologists were all registered.

This study was approved by the local ethics committee as part of a larger protocol.

\section{RESULTS}

We reviewed 450 medical charts. Forty three PD patients who used or were using clozapine were enrolled in this study. Table 1 depicts demographic and clinical features of these patients at the moment they started clozapine.

Women comprised $55.8 \%$ of patients. The mean age of the patients at diagnosis was 53.5 years (range: $30-75$ ). The patients had a mean age of 64 years (36-85) when clozapine was prescribed. They had mean disease duration of 13.8 years and had been attending the clinic for an average of 7.5 years. Their mean UPDRS score at the moment of clozapine initiation was 55 (range: 19.5-121). They had an average H\&Y score of 3 and ADL of 60 . The mean dose of levodopa was of $762.5 \mathrm{mg} /$ day for an average of 9.5 years (range: 1-19) at the time clozapine was introduced. Thirty two patients $(74.4 \%)$ were taking other anti-parkinsonian medications when clozapine was initiated.

Most patients presented motor (95.3\%), behavioral $(88.4 \%)$ and autonomic symptoms (72.1\%). Falls affected $44 \%$ of PD patients. Levodopa-related motor symptoms included: wearing off and/or on-off phenomena (81\%) and dyskinesias (88\%). Behavioral symptoms included: depression (55\%), sleep disturbances (58\%), psychosis (72\%), dementia (55\%). Autonomic complications comprised orthostatic hypotension (41\%), sexual impotence (9\%), urinary incontinence (25\%) and intestinal constipation (34\%).

Clozapine was indicated for dyskinesia in 17 patients, for psychosis in 15 and for both indications simultaneously in 11. The average maximum dose of clozapine used was $69.6 \mathrm{mg} /$ day (range: 12.5-225). Seventeen patients used it for less than one year. The remaining twenty-six patients were in use of clozapine for a mean of 3.5 years.

Twenty six subjects (60.5\%) had noticeable adverse clinical effects after clozapine start. Nine of them referred more than one side effect. The effects recorded were ex-
Table 1. Demographic and clinical features of 43 Parkinson disease patients at the moment they started clozapine.

\begin{tabular}{lcc}
\hline & Mean value \pm SD & Median value [range] \\
\hline Age & $64.3 \pm 13.0$ & $67[36-85]$ \\
Disease duration (years) & $10.9 \pm 4.4$ & $11[0-19]$ \\
L-dopa (mg/day) & $762.5 \pm 496.3$ & $625[187.5-3.150]$ \\
UPDRS & $55 \pm 24$ & $53[19.5-121]$ \\
H\&Y & $3 \pm 1$ & $3[1.5-5]$ \\
ADL & $60 \pm 18$ & $67.5[30-90]$ \\
\hline
\end{tabular}

UPDRS, Unified Parkinson Disease Rating Scale, H\&Y, Hoehn \& Yahr; ADL, Schwab \& England Activities of Daily Living Scale.

cessive sedation (13), sialorrhea (7), neutropenia (3), plaquetopenia (1), urinary incontinence (1), epigastric pain and diarrhea (1), nausea, vomiting and severe intestinal constipation (1), diplopia (1), hallucination (1) and agitation (1).

Clozapine was interrupted in 20 patients for different reasons, including: death (5), clozapine side effects (7), worsening of the motor condition (2) and others (6). The causes of death were not related to clozapine. Side effects which led to discontinuation of treatment were: neutropenia (3), plaquetopenia (1), severe constipation with bowel obstruction (1), hallucination (1) and agitation (1).

Table 2 depicts the outcome of clozapine use. Twenty two $(51.2 \%)$ patients presented partial improvement while $7(16.3 \%)$ had significant improvement of the clinical condition that required clozapine. Nine $(20.9 \%)$ had no improvement and the remaining five patients had the treatment discontinued before the outcome could have been adequately assessed.

There was no significant difference in age $(p=0.15)$, length of disease $(p=0.77)$ and UPDRS scores $(p=0.16)$ between patients who improved in comparison with patients who presented no clinical improvement or had an early clozapine withdrawn.

\section{DISCUSSION}

The present naturalistic study suggests that clozapine may provide an improvement of motor and behavioral symptoms of advanced PD, when its use is feasible. Some factors such as its cost, unwillingness to accept its risks,

Table 2. Outcome related to clozapine use in 43 Parkinson disease patients.

\begin{tabular}{lccccc}
\hline & $\begin{array}{c}\text { Number of } \\
\text { patients }\end{array}$ & $\begin{array}{c}\text { Significant } \\
\text { improvement }\end{array}$ & $\begin{array}{c}\text { Partial } \\
\text { improvement }\end{array}$ & No change & $\begin{array}{c}\text { Withdrawn before } \\
\text { outcome evaluation }\end{array}$ \\
\hline Dyskinesias & 17 & 2 & 10 & 3 & 2 \\
Psychosis & 15 & 5 & 6 & 2 & 2 \\
Both & 11 & 0 & 6 & 4 & 1 \\
Total & 43 & 7 & 22 & 9 & 5 \\
\hline
\end{tabular}


the inconvenience of the weekly blood tests, and intolerance to its side effects might limit the use of clozapine. This later issue is particularly true for this group of patients in view of the advanced age, their compromised general health status, and the possibility of drug interactions ${ }^{6}$.

To the best of our knowledge this is the first study to report the use of clozapine in a series of Brazilian PD patients. Although it is retrospective and uncontrolled, constituting a clear limitation, it has one of the largest cohort of PD patients reported in the literature. Results are concordant with other retrospective studies performed in developed countries, including the beneficial role of clozapine in situations not just restricted to psychosis in PD and the lower tolerability to the drug by these patients in comparison to the young adults with schizophrenia.

In a previous retrospective study which enrolled 49 patients, Wagner et al. evaluated the efficacy of clozapine with regard to psychosis and motor symptoms of $\mathrm{PD}^{7}$. These authors demonstrated that clozapine improved psychotic symptoms in $92 \%$ of patients. Despite the fact that only $6 \%$ of these patients obtained complete relief of their psychotic symptoms, the improvement achieved in most patients was sufficient to allow the maximization of levodopa therapy.

Similar findings of the efficacy of clozapine in PD were found by other authors. Trosch et al. conducted a multicentered and retrospective study in four American Clinics of Movement Disorders. ${ }^{8}$. This study comprised 172 consecutive PD patients. Almost $90 \%$ of patients demonstrated improvement of psychotic symptoms, but other symptoms such as anxiety, depression, hypersexuality and insomnia also ameliorated. Klein et al. interviewed and analyzed charts of 32 patients who received clozapine for psychosis and they observed that the drug improved psychotic symptoms in all participants ${ }^{9}$. Fernandez et al. analyzed the results of long-term use of clozapine for psychosis in 39 patients with parkinsonism, 79\% presenting $P D^{5}$. The authors stated that an expressive proportion of patients demonstrated good response or complete resolution of psychosis ( $85 \%$ and $13 \%$, respectively) following clozapine. However, before the entry in the study, $20 \mathrm{pa}-$ tients were excluded because they had used clozapine for less than two years. These 20 patients interrupted the drug due to either lack of efficacy or intolerable side effects.

In our study, performing an intention to treat analysis (i.e., including the participants who interrupted the treatment for several reasons), improvement in psychotic and motor symptoms was noticed in $65.4 \%$ and $64.3 \%$ of participants, respectively. Response of some motor and sensory symptoms in PD to clozapine was also noticed by Trosch et al. ${ }^{8}$. However, as clozapine efficacy allowed adjustment of levodopa doses, caution should be taken in interpreting these data. In the study conducted by Wagner et al., the effect of clozapine on motor symptoms, as assessed by UPDRS, did not reach statistical significance. In addition, only $12 \%$ of patients reported side effects ${ }^{7}$. Differences in sample characteristics (such as higher proportion of women and higher UPDRS mean scores in our study) may account for these differences in efficacy and tolerability.

The most common side effects in the study conducted by Fernandez et al. were excessive sedation (30\%) and sialorrhea $(10 \%)^{5}$. Klein et al. also reported that 3 patients out of 32 stopped medication due to excessive sedation? In the present study, excessive sedation was also the most common side effect reported and a major limitation to increase dosage. Nevertheless, the majority of cases with sedation and sialorrhea did not discontinue treatment.

It must be mentioned that delirium may occur in late stages of PD and worsen with clozapine therapy. This syndrome may be equivocally mistaken as psychosis by patient's family and physicians leading to clozapine prescription. Interestingly, it has been reported that patients who presented delirium possibly due to clozapine evolved with clinical remission of the confusional state within one week despite the persistence of clozapine in low dose ${ }^{6}$.

Although no case of agranulocytosis was reported by Fernandez et al., two patients out of 67 exhibited transient leukopenia ${ }^{5}$. The incidence of neutropenia seen on our clinic was $6.9 \%$. In one case, it was transient neutropenia and in the other two it persisted, preventing clozapine reintroduction.

Some prospective studies confirmed the benefits of its use in PD. Durif et al. made a multicentered, parallel, double-blinded and placebo controlled study to investigate the efficacy and safety of clozapine in the treatment of levodopa-induced diskinesias ${ }^{10}$. Clozapine proved to be an effective drug in these cases, with a rate of adverse effects similar to placebo.

Other double-blind placebo-controlled studies showed clozapine's efficacy in drug-induced psychosis ${ }^{11-13}$. Pollak et al. compared the efficacy and safety of clozapine in 60 patients with drug induced-psychosis in PD through parallel, double-blinded study with placebo. ${ }^{13}$ These authors confirmed that clozapine at low doses improves drug-induced psychosis in PD without significant worsening of motor function. In addition, other studies compared the efficacy of clozapine with risperidone ${ }^{14}$, olanzapine ${ }^{15,16}$ or quetiapine ${ }^{17-19}$ in anti-parkinsonian druginduced psychosis. Although these drugs were effective in ameliorating psychotic symptoms, risperidone and olanzapine frequently aggravated parkinsonism. Quetiapine has been associated with improvement of psychosis and 
dyskinesias, without worsening of motor symptoms ${ }^{17-19}$. Some studies have demonstrated that clozapine is more effective in reducing psychotic symptoms and dyskinesias, and may improve parkinsonism ${ }^{19}$. However, two out of our 43 patients showed worsening in UPDRS scores. This observation is in agreement with other studies using high doses of the drug ${ }^{8}$. In our study, clozapine seems to have been used on higher doses compared with other recent studies ${ }^{17,18}$. The worsening seen on motor function is probably due to many variables: disease progression, high clozapine dosage, changes in adjunctive PD medications, or even an antagonism on D2 receptor ${ }^{8}$.

In conclusion, clozapine may be of special usefulness in PD if patients tolerate its adverse effects. As perspective, it would be helpful to identify factors able to predict the patient's response and tolerability. Due to the limitations inherent to a retrospective chart review, it's not possible to accomplish these objectives. For that, other prospective analyses are required.

\section{REFERENCES}

1. Diamond A, Jankovic J. Treatment of advanced Parkinson's disease. Expert Rev Neurother 2006;6:1181-1197.

2. Frieling $\mathrm{H}$, Hillemacher $\mathrm{T}$, Ziegenbein M, Neundorfer B, Bleich S. Treating dopamimetic psychosis in Parkinson's disease: structured review and meta-analysis. Eur Neuropsychopharmacol 2007;17:165-171.

3. Friedman JH. Atypical antipsychotics in the EPS-vulnerable patient. Psychoneuroendocrinology 2003;28(Suppl 1):S39-S51.

4. Friedman JH, Fernandez HH. Atypical antipsychotics in Parkinson-sensitive populations. J Geriatr Psychiatry Neurol 2002;15:156-170.
5. Fernandez HH, Donnelly EM, Friedman JH. Long-term outcome of clozapine use for psychosis in parkinsonian patients. Mov Disord 2004;19: 831-833.

6. Musser WS, Akil M. Clozapine as a treatment for psychosis in Parkinson's disease: a review. J Neuropsychiatry Clin Neurosci 1996;8:1-9.

7. Wagner ML, Defilippi JL, Menza MA, Sage JI. Clozapine for the treatment of psychosis in Parkinson's disease: chart review of 49 patients. J Neuropsychiatry Clin Neurosci 1996;8:276-280.

8. Trosch R, Friedman J, Lannon M, et al. Clozapine use in Parkinson's disease: a retrospective analysis of a large multicentered clinical experience. Mov Disord 1998;13:377-382.

9. Klein C, Gordon J, Pollak L, Rabey JM. Clozapine in Parkinson's disease psychosis: 5-year follow-up review. Clin Neuropharmacol 2003;26:8-11.

10. Durif F, Debilly B, Galitzky M, et al. Clozapine improves dyskinesias in Parkinson disease: a double-blind, placebo-controlled study. Neurology 2004;62:381-388.

11. The French Clozapine Parkinson Study Group. Clozapine in drug-induced psychosis in Parkinson's disease. Lancet 1999;353:2041-2042.

12. The Parkinson Study Group. Low-dose clozapine for the treatment of drug-induced psychosis in Parkinson's disease. N Engl J Med 1999;340:757-763.

13. Pollak P, Tison F, Rascol O, et al. Clozapine in drug induced psychosis in Parkinson's disease: a randomised, placebo controlled study with open follow up. J Neurol Neurosurg Psychiatry 2004;75:689-695.

14. Ellis T, Cudkowicz ME, Sexton PM, Growdon JH. Clozapine and risperidone treatment of psychosis in Parkinson's disease. J Neuropsychiatry Clin Neurosci 2000;12:364-369.

15. Chacon J. Clozapine and olanzapine in the treatment of the psychotic disorders in Parkinson's disease. Rev Neurol 2004;39:655-660.

16. Goetz CG, Blasucci LM, Leurgans S, Pappert EJ. Olanzapine and clozapine: comparative effects on motor function in hallucinating PD patients.Neurology 2000;55:789-794.

17. Morgante L, Epifanio A, Spina E, et al. Quetiapine versus clozapine: a preliminary report of comparative effects on dopaminergic psychosis in patients with Parkinson's disease. Neurol Sci 2002;23 (Suppl 2):S89-S90.

18. Morgante L, Epifanio A, Spina E, et al. Quetiapine and clozapine in parkinsonian patients with dopaminergic psychosis. Clin Neuropharmacol 2004;27:153-156.

19. Merims D, Balas M, Peretz C, Shabtai H, Giladi N. Rater-blinded, prospective comparison: quetiapine versus clozapine for Parkinson's disease psychosis. Clin Neuropharmacol 2006;29:331-337. 